\title{
Mutagenic Activity of Incense Smoke in Comparison to Formaldehyde and Acetaldehyde in Salmonella typhimurium TA102
}

\author{
H. L. Chang, ${ }^{1}$ M. L. Kuo, ${ }^{2}$ J. M. Lin $^{1}$ \\ 'Institute of Environmental Health, College of Public Health, National Taiwan \\ University, Room 1451, No. 1, Section 1, Jen-Ai Rd, Taipei, \\ Taiwan, Republic of China \\ ${ }^{2}$ Institute of Toxicology, College of Medicine, National Taiwan University, Room \\ 544, No. 1, Section 1, Jen-Ai Rd, Taipei, Taiwan, Republic of China \\ Received: 12 April 1996/Accepted: 1 November 1996
}

Epidemiological studies have postulated that burning Chinese incense would cause nasopharyngeal cancer (Schoenotol and Gibbard, 1967), childhood leukemia (Lowengard et al., 1987), and childhood brain tumor (Martin et al., 1982). The incense smoke containing polycyclic aromatic hydrocarbons (Schoenotol and Gibbard, 1967) and aliphatic aldehydes (Lin and Wang, 1994 a; Lin and Tang, 1994 b) have been indentified. For carcinogenicity, numerous studies demonstrated that exposing rats to formaldehyde and acetaldehyde would result in squamous cell carcinomas in nasal cavities (Albert et al., 1982; Kerns et al., 1983; Woutersen et al., 1984; Woutersen et al., 1986). Formaldehyde caused mutagenic activity in Salmonella typhimurium TA102 and TA1535, but acetaldehyde and acrolein did not (Flora et al., 1984; Marnett et al., 1985; Curieux et al., 1993; Temcharoen and Thilly, 1983).

Incense smoke was also found to be mutagenic to $S$. typhimurium TA98, TA100 and TA104 in the presence of exogenous activation system; however, no mutagenic activity was detected in extracts of unburned incense (Sato et al., 1980; Rasmussen, 1987). The mutagenic activity of incense smoke from burning incense with bamboo stick was higher than that of smoke from burning incense without bamboo stick (Lofroth, Stensman and Margareta, 1991). Burning incense with bamboo stick was found to generate a higher level of formaldehyde (Lee and Lin, 1996).

The mutagenic activity of incense smoke has been demonstrated in vitro in various assay systems; however, to our knowledge, no reports of the mutagenic activity of components of incense smoke were found. In this study, we compared the mutagenic activity of incense smoke with aliphatic aldehydes such as formaldehyde and acetaldehyde in Salmonella typhimurium TA102. 
A joss stick, named Chinese Incense Black, was obtained from a local vendor. It was burned in a polypropylene made chamber having a size of $68 \times 48 \times 44 \mathrm{~cm}^{3}$, under the controlled conditions of flowrate of $3.0 \mathrm{~L} / \mathrm{min}$, temperature ranging from $24^{\circ} \mathrm{C} \sim 25^{\circ} \mathrm{C}$ and relative humidity of $47.7 \% \sim 52.5 \%$. Smoke was collected by drawing the plume to a three-piece cassette holder which contained a glass fiber filter ( $1 \mu \mathrm{m}$ poresize, $24 \mathrm{~mm}$ diameter, Whatman, England), and through a gas washing bottle ( $20 \mathrm{~mL}$, Tung Kuang, Taiwan) which contained $10 \mathrm{~mL}$ deionized water. The sampling flowrate was $1.0 \mathrm{~mL} / \mathrm{min}$ and the sampling time was $30 \mathrm{~min}$. A blank was also prepared in the same situation before a joss stick was ignited. The particulate materials in a filter were extracted for 20 min with $3 \mathrm{~mL}$ deionized water in ultrasonic vibration. Next, its supernatant was taken for mutagenesis testing and aliphatic aldehydes determination.

To determine aliphatic aldehydes in both vapor phase extract and particulate extract, an aliquot of $0.3 \mathrm{~mL} 0.3 \mathrm{mg} / \mathrm{mL}$ 2,4-dinitrophenyl hydrazine (Sigma, USA; 2,4DNPH) was added into $0.7 \mathrm{~mL}$ aqueous extract of incense smoke to form aldehyde2,4-dinitrophenylhydrazones which were determined via a high performance liquid chromatograph (HPLC, model 590, Waters, USA) equipped with a UV detector at $\lambda \max =254 \mathrm{~nm}$ (model 441, Waters, USA). An aliquot of $10 \mu \mathrm{L}$ sample was injected into HPLC with a column of C18 (250 X 4 mm, 100RP-18, Lichrospher) and a mobile phase of acetonitrile/water $(60 / 40 \mathrm{VN})$ at a flowrate of $1.0 \mathrm{~mL} / \mathrm{min}$. The compound of 4-fluorobenzonitrile (46680, Fluka, Switzerland) functioned as an internal standard for calculating the relative retention times of aliphatic aldehyde2,4-dinitrophenylhydrazones and quantifying.

Polycyclic aromatic hydrocarbons (PAHs) were also detected for vapor phase aqueous extract of incense smoke ("vapor" extract), but not for particulate extract because the amount of particulate extract was insufficient to determine the PAHs. To determine PAHs, $5 \mathrm{~mL}$ of "vapor" extract were extracted five times with $1 \mathrm{~mL}$ portions of cyclohexane (2827, Merck, Germany). A $2 \mu \mathrm{L}$ extract was injected into the HP 5988A GC/MS with HP 59970 MS Chem Station to identify the PAHs. The column was $30 \mathrm{~m} \times 0.25 \mathrm{~mm}$ (ID) SE-54 and the ionization potential was 70 eV.

For mutagenicity assay, Salmonella typhimurium strain TA102 was kindly provided by Dr. Shwu-Fei Lee of Development Center for Biotechnology, Taiwan. The assay methods of Ames et al. were basically followed, with the use of preincubation method (Maron and Ames, 1983). Preincubation tests for mutagenic activity were performed by incorporating $0.1 \mathrm{~mL}$ bacterial suspension with $0.1 \mathrm{~mL}$ "vapor" extract (or particulate extract) and $0.5 \mathrm{~mL} 0.2 \mathrm{M}$ sodium phosphate buffer in a centrifugal tube. Tubes containing reaction mixtures were incubated for 30 
min in a water bath; $2 \mathrm{~mL}$ of soft agar was also added to each tube. The tubes were vortexed and their contents were poured onto mininal agar plates, which were allowed to stand for $30 \mathrm{~min}$ and incubated at $37^{\circ} \mathrm{C}$ for $48 \mathrm{hrs}$. The compound mitomycine C (M-0503, Sigma, USA) was used as a positive control. The same procedure was applied in mutagenic testing for formaldehyde or acetaldehyde solution which was prepared by dissolving formaldehyde $(37 \%, 4003$, Merck, Germany) or acetaldehyde (00071, Fluka, Switzerland) in deionized water.

Next, the mutagenic activity of incense smoke extracts and aldehyde solutions was assessed by conducting doseresponse experiment using concentration that did not produce significant bacterial killing. Also, the slope of linear response curve was calculated as revertants per microgram of material indicated as formaldehyde. At least 3 data points, each based on $6 \sim 9$ replicate plates, were used to calculate the slope. Control values were subtracted prior to calculation of the slopes.

\section{RESULTS AND DISCUSSION}

Chemical analysis was performed to find whether vapor extract of incense smoke contained aliphatic aldehydes and PAHs. Formaldehyde and acetaldehyde were found, but PAHs were not disclosed as the GC/MS chromatogram in Figure 1 indicated. The aliphatic aldehydes concentration in vapor extract of incense smoke was $99.985 \mu \mathrm{g} / \mathrm{mL}$ formaldehyde and $17.205 \mu \mathrm{g} / \mathrm{mL}$ acetaldehyde. The other chemical composition of this vapor extract was not explored further.

Particulate collected on a filter was extracted with deionized water ("particulate" extract). This particulate extract also contained $38.742 \mu \mathrm{g} / \mathrm{mL}$ formaldehyde and $3.294 \mu \mathrm{g} / \mathrm{mL}$ acetaldehyde. However, PAHs were not explored.

With strain TA102, mutagenic activity was found in both particulate and vapor extract and formaldehyde solution in Figure 2. For pure formaldehyde solution, toxic effect to TA102 occurred when formal dehyde concentration was higher than $18 \mu \mathrm{g} /$ plate. However, the pure acetaldehyde solution had no effect of mutagenicity in Figure 3; however, it became toxic to TA102 when acetaldehyde concentration was over $5000 \mu \mathrm{g} /$ plate. Over the range of concentration of material indicated as formaldehyde, the response was approximately linear as shown in Figure 4. Table 1 calculates the slopes (revertants/ $\mu \mathrm{g}$ ) of dose-response curves. The particulate extract with 60.96 revertants/ $\mu \mathrm{g}$ appeared to be the most active in comparison to vapor extract with 33.33 revertants/ $\mu \mathrm{g}$ and formaldehyde solution with 20.14 revertants/ $\mu \mathrm{g}$.

The potency of vapor extract as mutagen appeared to be high when measured against a known concentration of formaldehyde solution. This finding indicates that vapor extract from incense smoke probably contains several water soluble 


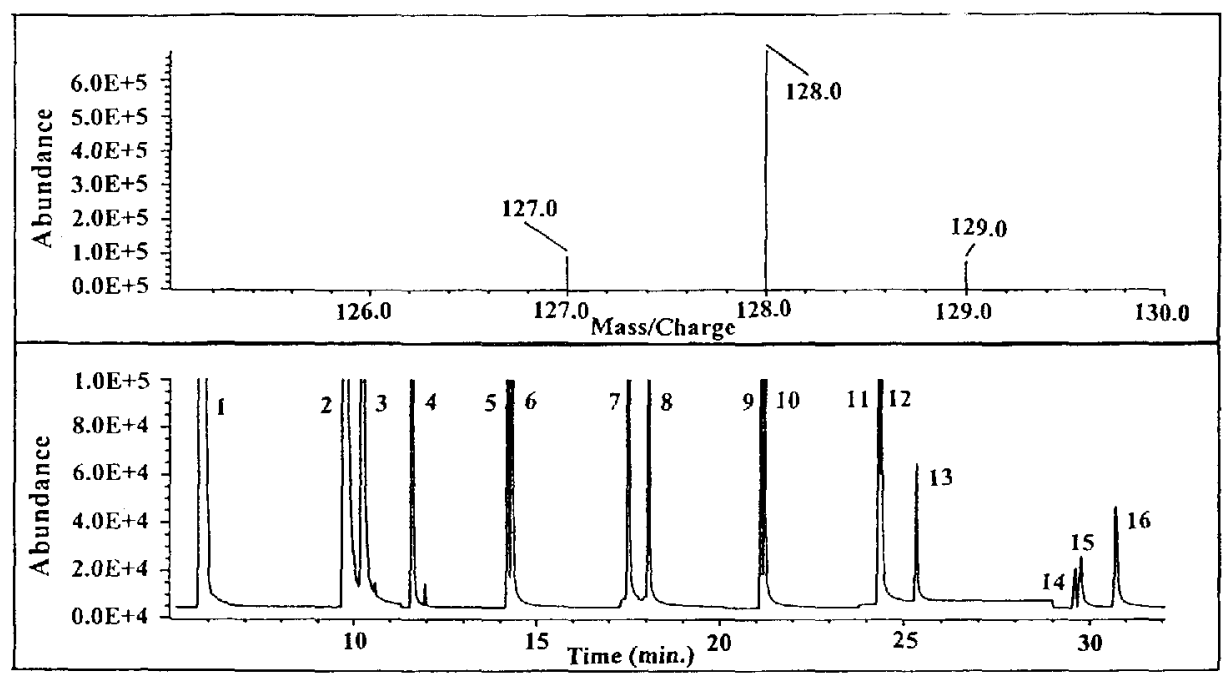

A
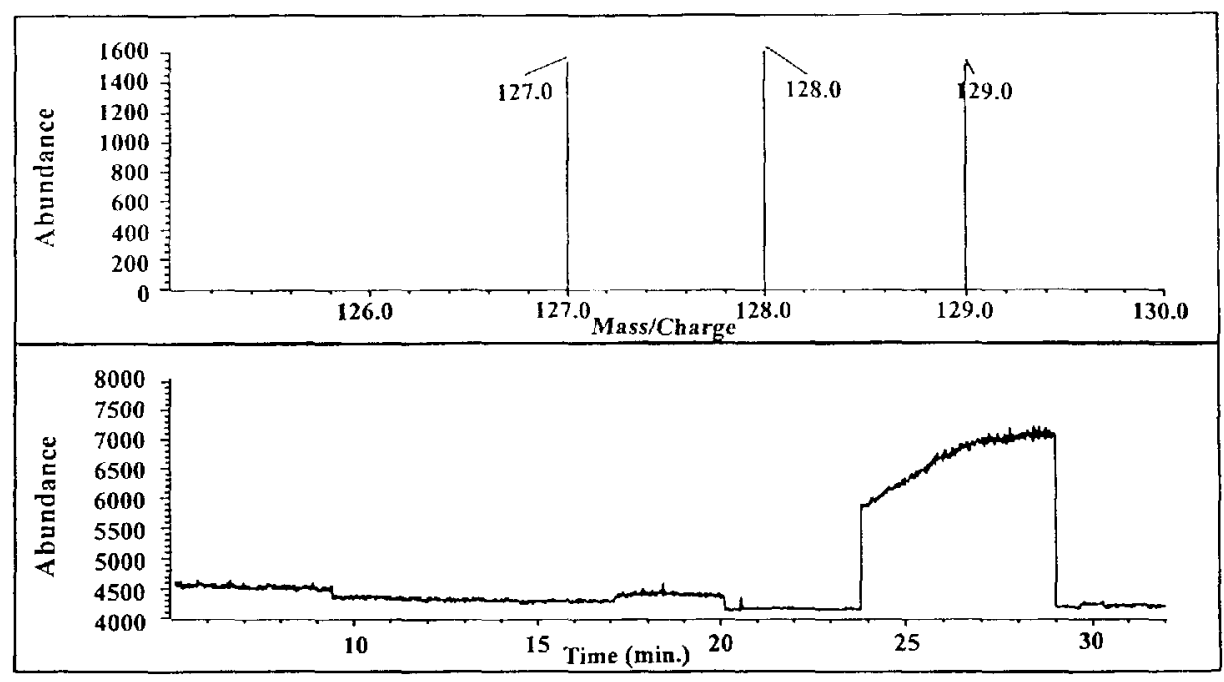

$\mathbf{B}$

Figure 1. GC/MS Chromatograms of polyaromatic hydrocarbons (A. Standard solution : 1.Nap, 2. AcPy, 3.Acp, 4.Flu, 5. PA, 6.Ant, 7. FL, 8.Pyr, 9.BaA, 10.Chr, 1 1. BbFL, 12. BkFL, 13.BaP, 14.IP, 15.DBA, 16. BghiP; $B$. Aqueous vapor extract of incense smoke) 

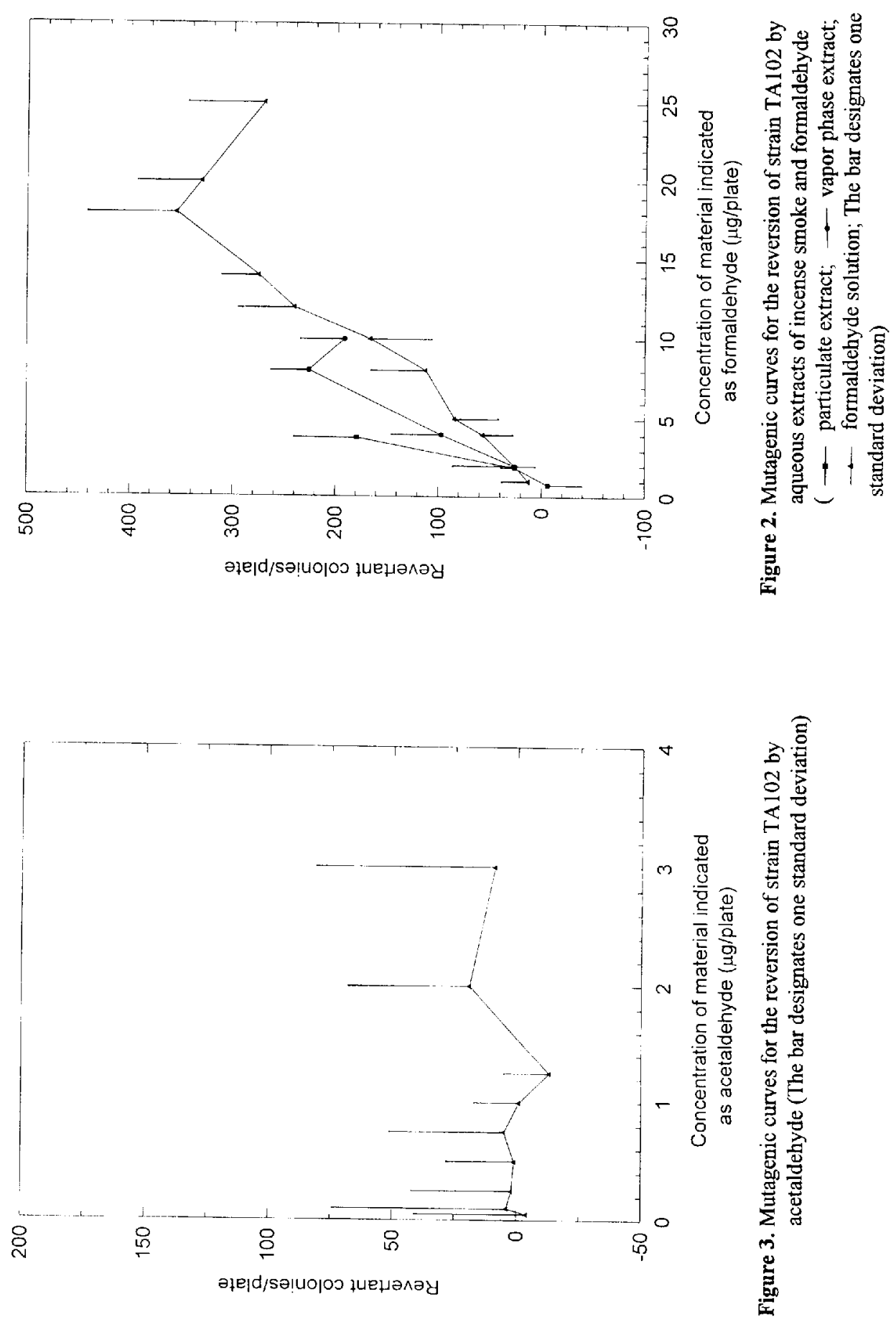


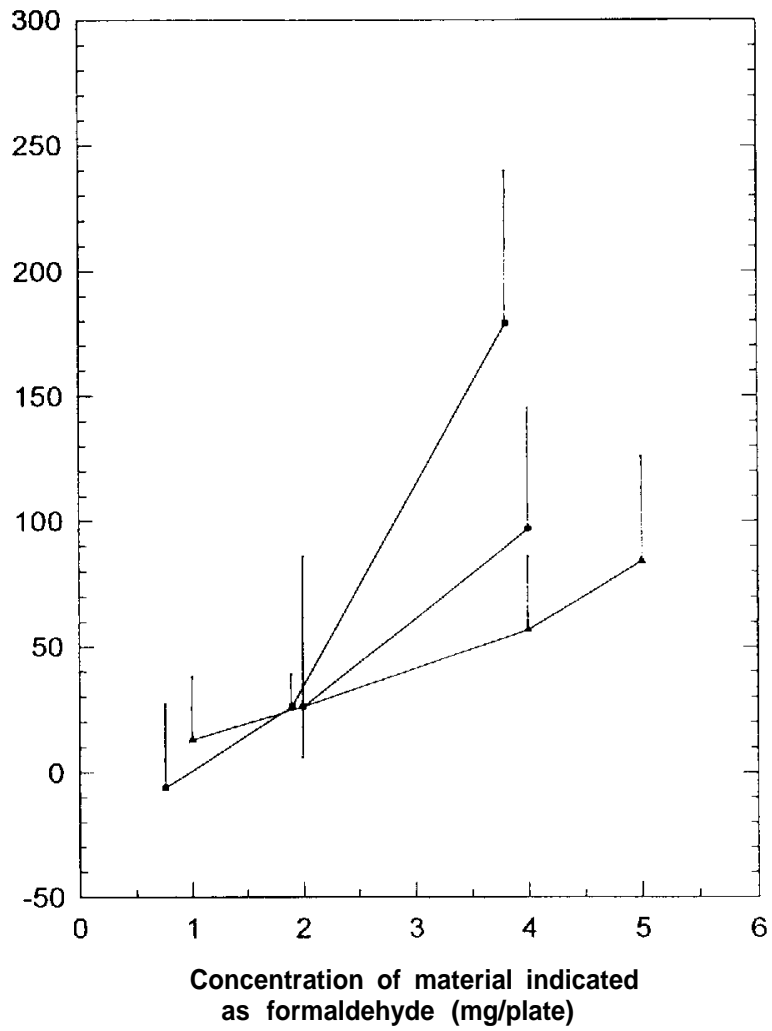

Fig. 4 Dose-response curves for the reversion of strain TA102 by aqueous extracts of incense smoke and formaldehyde ( - . particulate extract; - - vapor phase extract; $\ldots$ formaldehyde solution)

Table 1. Reversion of strain by aqueous extract of incense smoke and formaldehyde solution

Test material

Particulate extract

Vapor phase extract

Formaldehyde solution

Postive control

Mitomycin $\mathrm{C}$
Calculated slopes of dose-response curve, revertants/ $\mu \mathrm{g}$ of material indicated as formaldehyde or mitomycin

\subsection{3}

20.14

1244.80 
mutagenic species in addition to formaldehyde. Comparing the mutagenic potencies of particulate extract reveals that the concentration of formaldehyde and acetaldehyde in particulate extract are markedly lower than vapor extract; however, the mutagenicity of particulate extract is higher than vapor extract. The mutagenic activity in the particulate extract is likely owing to few relatively highly active compounds in addition to formaldehyde. Those highly active compouds may not dissolve in water, but may suspend with particulate in water. Those results suggest that incense smoke contains a somewhat smaller fraction of mutagens with a higher mutagenic potency than that of formaldehyde.

Results in this study demonstrate that incense smoke not only contains oxidative mutagens, but can cause frameshift mutation. However, people are used to burning incense for religious activities in temple and homes in Taiwan. Thus, emphasizing the hazardous nature of incense smoke is important.

Acknowledgments. We thank Dr. I-Fu Hung, Institute of Nuclear Science National Tsing Hua University Hsinchu, Taiwan, R.O.C. for technicual assistance and generously allowing us use of his GC/MS.

\section{REFERENCES}

Albert RE, Sellakumar AR, Laskin S, Kuschner M, Nelson N, Snyder CA (1982) Gaseous formal dehyde and hydrogen chloride induction of nasal cancer in the rat. J Natl Cancer Inst 68:597-602

Curieux FL, Marzin D, Erb F (1993) Comparison of three short-term assays: Results on seven chemicals. Mut Res 319:223-236

Flora SD, Camoirano A, Zanacchi P, Bennicelli C (1984) Mutagenicity testing with TA97 and TA102 of 30 DNA-damaging compounds, negative with other Salmonella strains. Mut Res 134:159-165

Kerns WD, Pavkov KL, Donofrio DJ , Gralla EJ, Swenberg J A (1983) Carcinogenicity of formaldehyde in rats and mice after long-term inhalation exposure. Cancer Res 43:4382-4392

Lee RS, Lin J M (1996) Gaseous aliphatic aldehydes in smoke from burning raw materials of Chinese joss stick. Bull Environ Contam Toxicol 57:361-366

Lin J M, Wang LH (1994 a) Gaseous aliphatic aldehydes in Chinese incense smoke. Bull Environ Contam Toxicol 53:374-381

Lin J M, Tang CS (1994 b) Characterization and aliphatic aldehyde content of particulates in Chinese incense smoke. Bull Environ Contam Toxicol 53:895901

Lofroth G, Stensman C, Margareta BS (1991) Indoor sources of mutagenic aerosol particulate matter: Smoking, cooking and incense burning. Mut Res 261:21-28 Lowengart RA, Peters J M, Cicioni C, Buckley J , Bernstein L, Preston-Martin S, 
Rappaport E (1987) Childhood leukemia and parents' occupational and home exposures. J Natl Cancer Inst 79(1):39-46

Marnett LJ, Hurd HK, Hollstein MC, Levin DE, Esterbauer H, Ames BN ( 1985) Naturally occurring carbonyl compounds are mutagens in Salmonella tester strain TA104. Mut Res 148:25-34

Maron DM, Ames BN (1983) Revised methods for the Salmonella mutagenicity test. Mut Res 113:173-215

Martin SP, Yu MC, Benton B, Henderson BE (1982) N-Nitroso compounds and childhood brain tumors: A case-control study. Cancer Res 42:5240-5245

Rasmussen RE (1987) Mutagenic activity of incense smoke in Salmonella typhimurium. Bull Environ Contam Toxicol 38:827-833

Sato S, Makino R, Takahashi Y, Sugimura T, Miyazaki T (1980) Mutagenicity of smoke condensates from joss sticks. Mut Res 77:31-36

Schoenotol R, Gibbard S (1967) Carcinogens in Chinese incense smoke (letter). Nature 216:612

Temcharoen P, Thilly WG (1983) Toxic and mutagenic effect of formaldehyde in Salmonella typhimurium. Mut Res 119:89-93

Woutersen RA, Appelman LM, Feron VJ, Van Der Heijden CA (1984) Inhalation toxicity of acetaldehyde in rats. II. Carcinogenicity study: Interim results after 15 months. Toxicology 31: 123-133

Woutersen RA, Appelman LM, Van Garderen-Hoetmer A, Feron VJ (1986) Inhalation toxicity of acetaldehyde in rats. III. Carcinogenicity study. Toxicology 41:213-231 